MATEC Web of Conferences 21, 04001 (2015)

DOI: $10.1051 /$ matecconf $/ 20152104001$

(C) Owned by the authors, published by EDP Sciences, 2015

\title{
Current assisted superplastic forming of titanium alloy
}

\author{
Guofeng Wang ${ }^{1, \mathrm{a}}$, Tao Zhao ${ }^{1}$, Yuelin Wang ${ }^{2}$, Xuesong Wu${ }^{1}$, Xiangxiang Dai ${ }^{1}$, and Qi Liu ${ }^{1}$ \\ ${ }^{1}$ National Key Laboratory of Precision Hot Processing of Metals, Harbin Institute of Technology, \\ Harbin 150001, China \\ ${ }^{2}$ Shenyang Aircraft Corporation, Shenyang 110850, China
}

\begin{abstract}
Current assisted superplastic forming combines electric heating technology and superplastic forming technology, and can overcome some shortcomings of traditional superplastic forming effectively, such as slow heating rate, large energy loss, low production efficiency, etc. Since formability of titanium alloy at room temperature is poor, current assisted superplastic forming is suitable for titanium alloy. This paper mainly introduces the application of current assisted superplastic forming in the field of titanium alloy, including forming technology of double-hemisphere structure and bellows.
\end{abstract}

\section{Introduction}

Titanium alloy has high specific strength, excellent mechanical property, good heat resistance and corrosion resistance, so it is widely used in the field of aviation and aerospace, shipping, chemical engineering, etc. [1]. But poor formability at room temperature makes it necessary to process titanium alloy at high temperature, so superplastic forming is the most effective way to process titanium alloy components. In traditional superplastic forming technology, the die and blank are heated in the furnace together, and there are shortcomings like slow heating rate, large energy loss, low production efficiency [2, 3]. However, current assisted superplastic forming technology uses electric heating technology, in which shortcomings of traditional superplastic forming can be overcome effectively.

In the technology of current assisted superplastic forming, metal is heated to forming temperature by high density current, then superplastic forming is carried out with current. By adopting electric heating, titanium alloy can be heated to forming temperature in tens of seconds or even less, so heating rate and production efficiency are high. Meanwhile, only the blank is heated, which results in high energy utilization and low loss of die. In conclusion, current assisted superplastic forming is more suitable for the industrial production of difficult-to-deformation materials like titanium alloy.

Electric heating technology is widely applied in many field of material processing, such as pulse current auxiliary sintering technology in the field of powder metallurgy [4], resistance heating technology in the field of semi-solid forming [5], etc. This paper mainly introduces research results

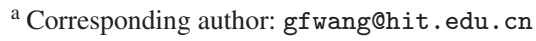

This is an Open Access article distributed under the terms of the Creative Commons Attribution License 4.0, which permits unrestricted use, distribution, and reproduction in any medium, provided the original work is properly cited. 


\section{MATEC Web of Conferences}

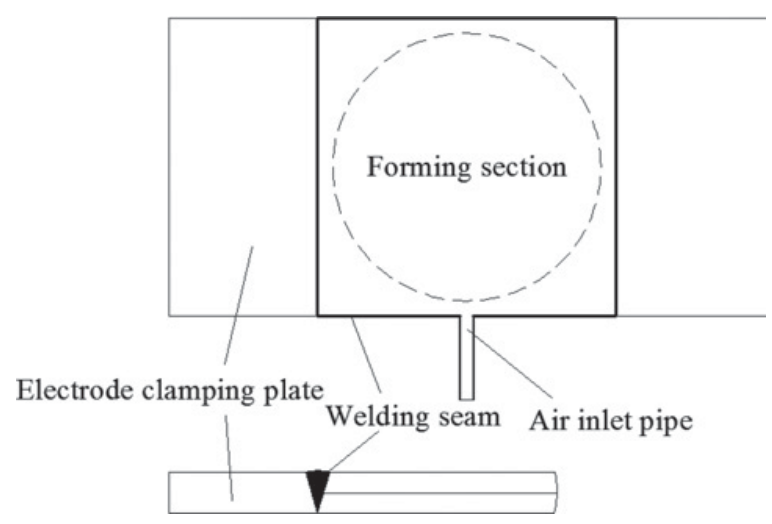

Figure 1. The sketch of the welding blank.

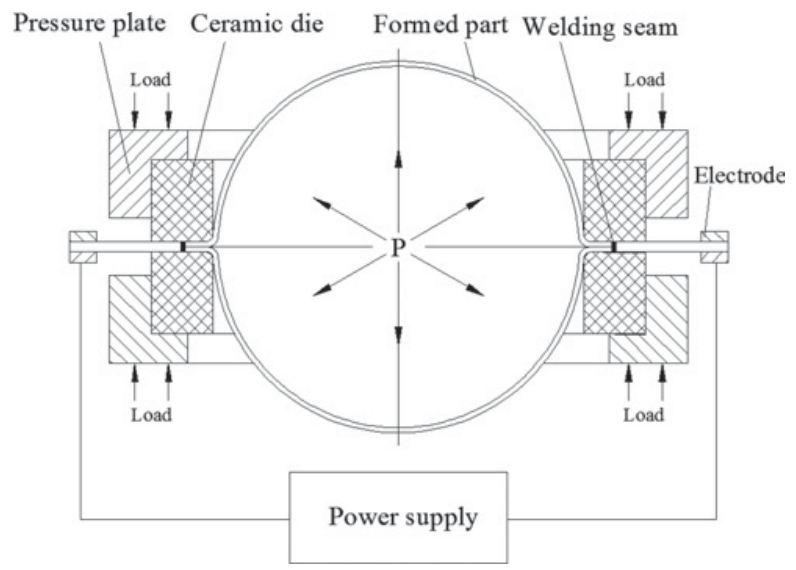

Figure 2. Testing apparatus of double-hemisphere structure.

of electric heating technology in the field of superplastic forming, and analyzes advantages of current assisted superplastic forming.

\section{Research results}

\subsection{Current assisted superplastic forming of double-hemisphere structure [6]}

The material of the double-hemisphere structure is Ti-6Al-4V. In the experiment, two pieces of blank were butt welded to form a confined space for seal, and electrode clamping plates and air inlet pipe were welded on the edge of it for ohmic heating and air bulging, as shown in Fig. ??. The testing apparatus is shown in Fig. ??. It includes power supply, electrode, ceramic die, pressure plate, etc. The ceramic die played a role of insulation, only making blank heated. The power supply, electrodes and welding blank formed an electric circuit, and the resistance of blank was larger than other parts, so the blank could be heated to superplastic forming temperature fleetly. When the temperature was stable, inert gas was inflated to bulge. In the experiment, the blank could be heated to $930{ }^{\circ} \mathrm{C}$ in $20 \mathrm{~s}$, so the heating rate was fast. 


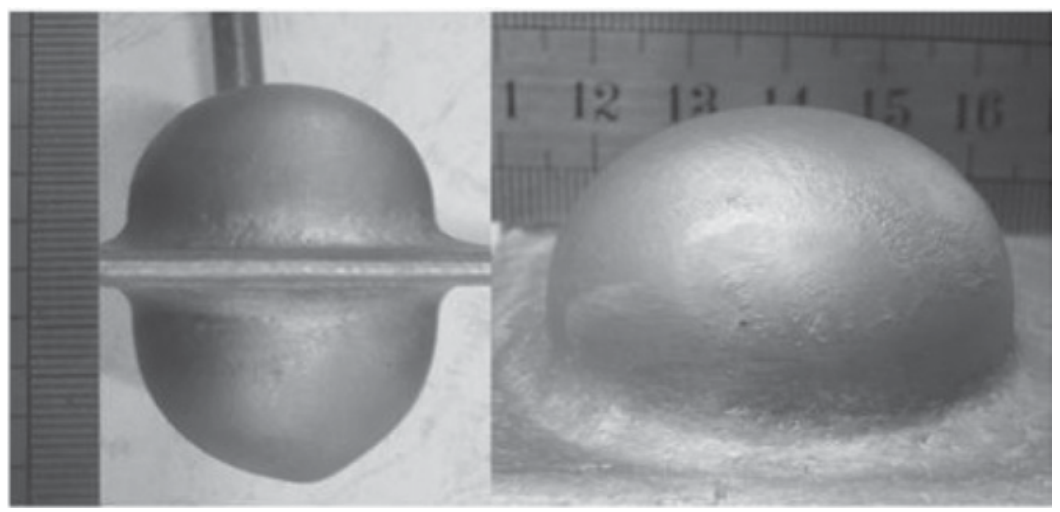

Figure 3. The double-hemisphere structure of titanium alloy.

Figure ?? is the double-hemisphere structure of titanium alloy formed by current assisted superplastic forming. The height-diameter ratio of double-hemisphere structure reaches above 1, and forming quality is good. So this technology can fully play the superplasticity of Ti-6Al-4V. Compared with traditional superplastic forming, process efficiency can increase by two times, and energy loss can reduce by about $80 \%$.

\subsection{Current assisted superplastic forming of bellows}

As the critical component of bellows expansion joint, bellows has functions of displacement compensation, vibration and noise reduction and seal, which makes it become the key component of equipment and pipeline in modern industry [7]. As titanium alloy has excellent corrosion resistance, heat resistance and high specific strength, it is used to manufacture bellows gradually. Current assisted superplastic forming is an ideal way to process titanium alloy bellows.

In order to avoid shortcomings of difficult deformation and uneven wall thickness, compound technology combining air bulging with axial loading was applied. Forming process is shown in Fig. ??, which is divided into three steps of bulging original ripples, closing die and filling cavity [8]. Figure ?? is the testing apparatus of small-size bellows designed based on the forming process. The testing apparatus consists of power supply, electrode, air pump, ceramic die, metal die, etc. The air pump played the role of axial loading, and the ceramic die played the function of insulation.

Small-size bellows of titanium alloy formed by current assisted superplastic forming is shown in Fig. ??. The wave height and wave thickness is $8 \mathrm{~mm}$. The material of small-size bellows is TA10. Wall thickness distribution of the bellows which fully touches the mould was analyzed, and the result shows that bellows has even distribution of wall thickness, and wall thickness at wave crest has the maximum thickness thinning, which is about 25\%. Meanwhile, microstructure was observed, and it is found that grains at crest and trough of bellows grow obviously by comparing with original microstructure.

According to the method of manufacturing small-size bellows, testing apparatus was improved to form large-size titanium alloy bellows with three ripples. Figure ?? is the large-size bellows. The wave height is $15 \mathrm{~mm}$, and the wave thickness is $14 \mathrm{~mm}$. The formed part has even distribution of wall thickness, less oxidation and no springback. In the forming process, blank was heated to forming temperature in tens of seconds, thus making forming cycle and energy loss reduce largely. 


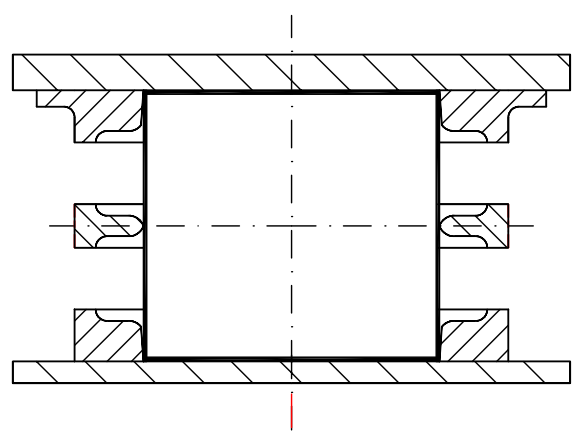

(a) original state

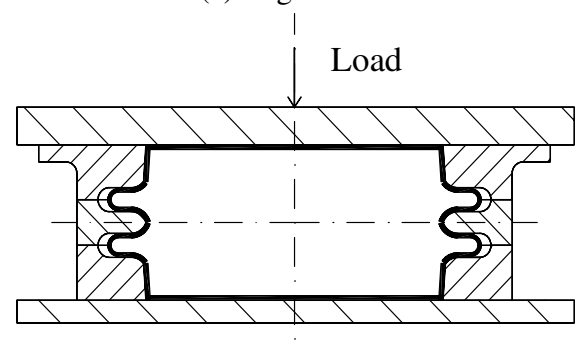

(c) closing die

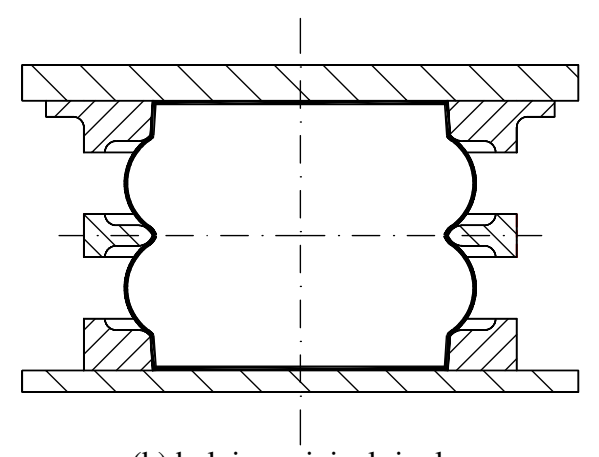

(b) bulging original ripples

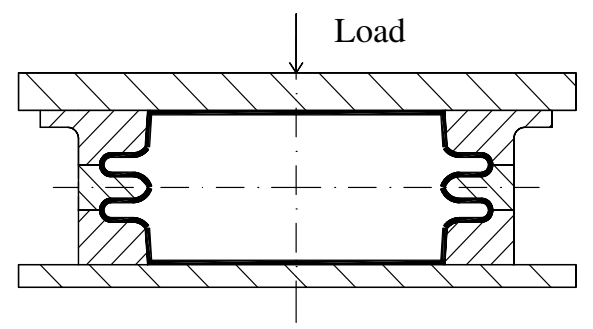

(d) filling cavity

Figure 4. The forming process of titanium alloy bellows.

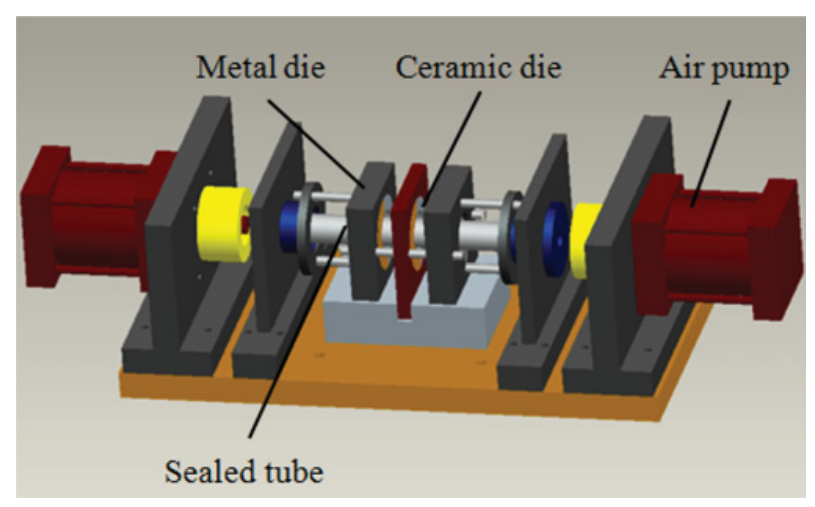

Figure 5. The testing apparatus of small-size bellows.

\section{Conclusions}

Double-hemisphere structure, small-size bellows with double ripples and large-size bellows with three ripples of titanium alloy were formed by current assisted superplastic forming successfully, which demonstrates that it is feasible to manufacture thin-walled parts of titanium alloy by current assisted superplastic forming. The application of electric heating technology results in shorter heating time, lower energy loss and higher production efficiency. And components formed by this technology are good quality with less oxidation and no springback. In conclusion, current assisted superplastic forming technology is suitable for rapid production of titanium alloy thin-walled parts. 


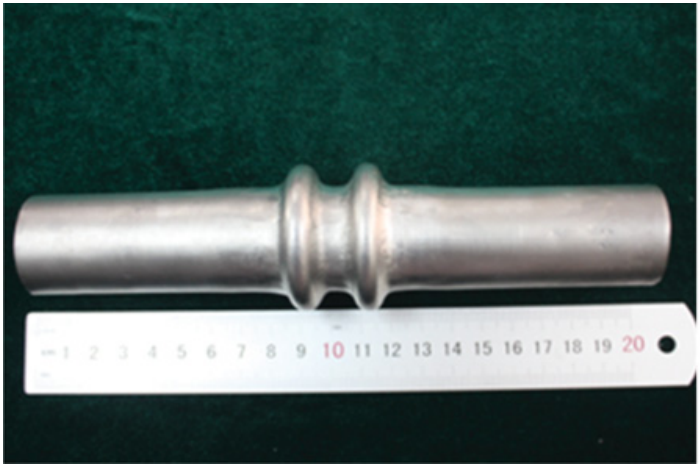

(a)

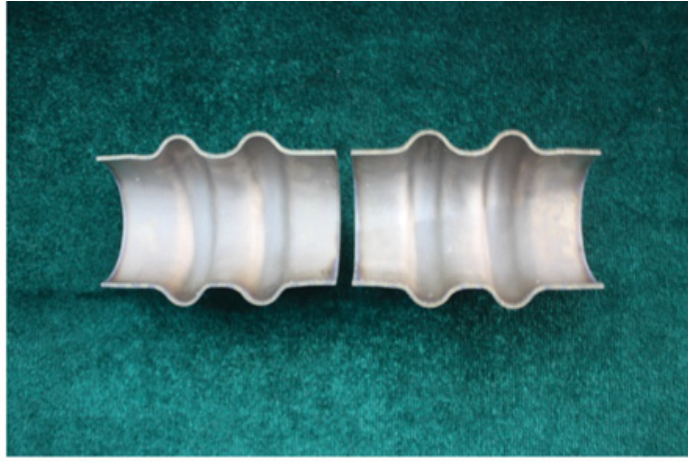

(b)

Figure 6. Small-size bellows of titanium alloy: (a) integral drawing, (b) sectional drawing.

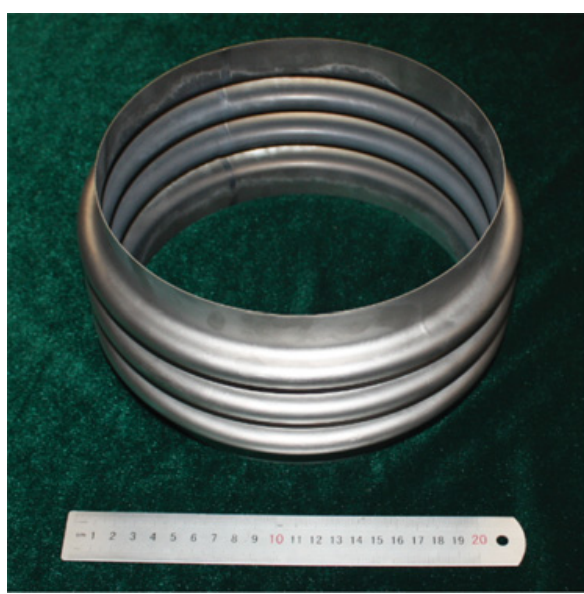

(a)

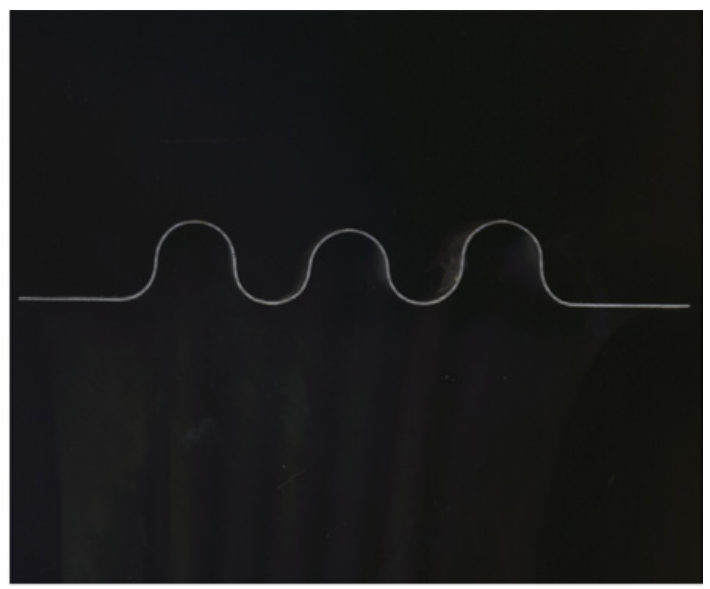

(b)

Figure 7. Large-size bellows of titanium alloy: (a) integral drawing, (b) sectional drawing.

This work was supported by the Program for Changjiang Scholars and Innovative Research Team in University (IRT1229) and the National Natural Science Foundation of China under grant number 51275129.

\section{References}

[1] H. Yang, L.X. Li, Q.D. Wang, L.G. Guo, JME, 46, 31 (2010)

[2] K.F. Zhang, G.F. Wang, D.Z. Wu, Z.R. Wang, J. Mater. Process. Technol., 151, 54 (2004)

[3] H.L. Xing, K.F. Zhang, Y. Qiao, Z.R. Wang, J. Mater. Process. Technol., 55, 43 (1995)

[4] C.P. Zhang, K.F. Zhang, G. Wang, Intermetallics, 18, 834 (2010)

[5] S. Maki, Y. Harada, K. Mori, H. Makino, J. Mater. Process. Technol., 125-126, 477 (2002)

[6] C. Li, K.F. Zhang, S.S. Jiang, Rare Metal Mat. Eng., 41, 1400 (2012)

[7] G. Subramanian, C. Raghunandan, J. Mater. Process. Technol., 41, 105 (1994)

[8] G. Wang, K.F. Zhang, D.Z. Wu, C.W. Wang, S.J. Yuan, J.Z. Wang, J. Mater. Process. Technol., 178, 24 (2006) 